\title{
EFFECTS OF LEARNING OUTCOMES ON TEACHING, LEARNING AND ASSESSMENT IN SOCIAL STUDIES IN TERTIARY INSTITUTIONS: ANALYSIS OF SELECTED OBE COMPLIANT COURSE OUTLINES AT THE UNIVERSITY OF BOTSWANA
}

\author{
Koketso Jeremiah \\ Senior Lecturer, \\ Department of Languages and Social Sciences Education, \\ Faculty of Education, University of Botswana, \\ Gaborone, Botswana
}

\begin{abstract}
:
This study was conducted to find out if the selected courses at the University of Botswana that have been prepared to meet the compliance standards of the Botswana Qualifications Authority (BQA) have any effects on teaching, learning and assessment processes with respect to the use of lesson outcomes. The study was guided by three research questions and these were: (1) What is the difference between lesson (or learning) outcomes and lesson objectives? (2) How are learning outcomes used in writing question items for tests and examinations? (3) How do learning outcomes improve teaching and learning or academic achievement and assessment in comparison with the use of learning objectives? These research questions were converted into three research objectives and these were: (1) To find out the difference between lesson (learning) outcomes and lesson objectives. (2) To find out how lesson (learning) outcomes are used to write question items for tests and examinations. (3) To find out how lesson outcomes improve teaching, learning or academic achievement and assessment in comparison with the use of lesson objectives. The courses that were analyzed to find answers to research questions and research objectives that guide this study were purposively sampled and they were five (5) of them. The study found that there was no clear difference between lesson outcomes and lesson objectives. It found that lesson outcomes were not used to write test or examinations questions unless they had been written as lesson objectives. The study also found that in comparison to lesson objectives, lesson outcomes did not improve teaching, learning (or students' academic achievement) and assessment. The study recommended that lesson outcomes be phased out and be replaced with lesson objectives as the latter (lesson objectives) were effective in ensuring that there is proper (or effective) teaching, learning and assessment instead of causing confusion to students, teachers and other stakeholders as learning outcomes do.
\end{abstract}

i Correspondence: email jeremiahk@ub.ac.bw 
Keywords: lesson outcomes, lesson objectives, Botswana Qualifications Authority, academic achievement, outcome-based education

\section{Introduction}

Outcome-based Education (OBE) is defined in various ways and some of these definitions will be examined on this paper. King and Evans (1991) define OBE as a programme that requires "... a change in traditional approaches to curriculum development, shifting the focus from objectives derived often from content or textbook outlines to objectives based on desired changes in the learner" (p1). Spady (1988) defines OBE as "...organizing for results, basing on what we do instructionally on the outcomes we want to achieve whether in specific parts of the curriculum or in the schooling process as a whole" (p5). Spady (1994) defines OBE as: "...clearly focusing and organizing everything in an educational system around what is essential for all students to be able to do successfully at the end of their learning experiences. This means starting with a clear picture of what is important for students to be able to do, then organizing curriculum, instruction, and assessment to make sure this learning ultimately happens" (p1). These definitions have one thing in common, and that is, they call for a change in focus from classroom objectives or outcomes to outcomes that a learner exhibits at the completion of the curriculum or educational programme; these are often referred to as exit outcomes. This is a challenge for a teacher who has been trained to teach within the guidance of classroom (or lesson) objectives, not lesson outcomes as these were not part of his/her training.

In order to achieve an Outcome-Based Education (OBE), two key elements need to be made available, and these are: (1) Outcomes and (2) Providing a conducive environment under which students can achieve these outcomes (Spady, 1994). These outcomes are not mere outcomes but exit outcomes, meaning that they appear at the end after the student has successfully met all the requirements of the programme or course. Spady (1988) clarifies this point by saying: "By designing our educational system to achieve clearly defined exit outcomes, we will free ourselves from the traditional rigidity of schools and increase the likelihood that all students will learn" (p4). So, outcomes are different from objectives that students need to achieve as determinants of the processes through which they attain the syllabus or curricula content or subject matter. However, there is often confusion between objectives and outcomes as you will see later. A conducive learning environment for students comprises availing opportunities and conditions that enable them to achieve the identified outcomes (Spady, 1994). It is now clear that the main difference between traditional methods of teaching (and curriculum design or development) and OBE is that while traditionalists focus on the objectives which describe or discuss the processes of learning and teaching, OBE practitioners or proponents focus on exit outcomes. Yet the two groups (or systems) use the same inputs, that is, teachers, materials and equipment to achieve the teaching and learning processes. These processes are ultimately followed by assessment which is the feedback loop to determine the effectiveness of the teaching and learning processes. 
Spady (1994) defines outcomes as: “...clear learning results that we want students to demonstrate at the end of significant learning experiences" (p2), or: "This ability to apply mental processing through the use of demonstration processes and verbs (like write, organize, design, or produce) corresponds to the definition of an outcome explained in this book" (p68). Oher verbs of this nature (that is, write, organize, design, or produce) appear on page 13 (Spady, 1994) and these are: "describe" and "explain". Such words are "..observable action verbs" (Spady, 1994, p13). On page 13 of his book, Spady (1994) gives an example of an outcome written using one of these observable or action verbs, and it reads: "...explain the major causes of inflation in capitalist economies..." (p13). Spady (1994) says that this question requires the learner to be equipped with the knowledge of the causes of inflation in these countries (capitalist in economic organization and planning) and the competence to explain them satisfactorily. Spady (1994) dismisses the use of words such as: know, understand, believe, appreciate, think, consider, reflect, remember, value, acquire, feel, and assimilate as unsuitable for writing or expressing lesson or learning outcomes. He justifies his dismissal of these terms for use to express outcomes because they fail to tell exactly what students are processing in their minds. In other words, they are general (or broad) as opposed to being specific. However, there is confusion that Spady (1994) further brings in, in connection with defining outcomes when he/she emphasizes that outcomes, especially exit outcomes, should be stated in broad terms because they describe the end result of the educational system after dismissing the use of broad terms such as know, think and appreciate. Spady (1994) states that: "...most exit outcomes are defined as broad performance capabilities, rather than as specific curriculum skills" (p3). This statement contradicts the one he made earlier when he/she said that outcomes should be stated in observable terms (Spady, 1994). Educators who do not use outcomes often use objectives in their curriculum design, development or teaching. Nowadays, most of the objectives used in curriculum design or teaching are based on Bloom's Taxonomy or classification (Bloom, 1956). This is because they are measurable or specific. A teacher who uses them knows exactly what students are expected to do at the end of any piece of instruction or lesson.

Spady and Marshall (1991) give examples of exit outcomes of educational programmes as: "...Collaborative Workers, who use effective leadership and group skills to develop and manage interpersonal relationships within culturally and organizationally diverse settings..." and "...Quality Producers, who create intellectual, artistic, practical, and physical products which reflect originality, high standards, and the use of advanced technologies..."(p71). Spady and Marshall (1991) also give three more exit outcomes and these are: "...Involved Citizens, who take the initiative to contribute their time, energies, and talents to improve the welfare of themselves and others and the quality of life in their local and global environments..." (p71) and "...Self-Directed Achievers who formulate positive core values in order to create a vision for their future, set priorities and goals, and monitor and evaluate their progress on them..."(p71) and "...Adaptable Problem Solvers, who anticipate, assess, and resolve the problems and challenges that accompany the rapidly changing political, economic, environmental, and social conditions of modern life..."(p71-72). 
In Figure 2 (p7) Spady (1988) gives levels of outcomes in an educational programme in a descending order as follows: Exit Outcomes, Programme Outcomes, Course Outcomes, Unit Outcomes, and Lesson Outcomes. This shows that an educational programme designed under the framework or guidance of OBE consists of outcomes for each level in an educational system. It is not clear how these sets of outcomes are coordinated to eliminate some inconsistencies that might arise causing inefficiency in an educational system or programme.

Before closing the issue of the nature of lesson outcomes it is necessary to briefly discuss the nature and origin of lesson objectives so that the reader who is not familiar with them can compare the two and hence understand the gist of the discussion.

\section{The Origin of Lesson Objectives}

The lesson objectives that are used for teaching, learning and assessment are derived from a classification of objectives developed by Benjamin Bloom. Bloom's Taxonomy has undergone some revisions since its founding. The revisions have brought about some improvements in the taxonomy. The Taxonomy is foundation of most, if not all, of the objectives that are used in many classrooms and other educational settings in many parts of the world where it has been most influential. There are three domains of knowledge in Bloom's Taxonomy and these are: Cognitive, Affective, and Psychomotor (1956). The Cognitive Domain is, however, the most widely used, mainly in the fields of social sciences and education. In order to make the reader understand the source of objectives, which is Bloom's Taxonomy, it (the taxonomy) will be briefly discussed here, and the focus will only be on the Cognitive Domain. For the sake of space and time, the other two domains (Affective and Psychomotor) will be left out of the discussion.

\subsection{The Cognitive Domain}

The major categories and processes associated with the Cognitive Domain are as follows: A. Remember: This means getting back the knowledge that occurred a long time ago. This means retrieving past knowledge into one's memory. The processes for retrieving this past knowledge include recalling and recognizing. The key words associated with these processes include: recognize, recall, and recite (Department of Curriculum Development and Evaluation, 1990; Anderson, et al., 2001).

B. Understand: This refers to the act of deriving or getting meanings from a variety of sources or settings and these may include: messages in the form of graphs, and written or oral messages. The cognitive processes involved in getting these meanings include: interpreting, classifying, summarizing, exemplifying, inferring, explaining, and comparing. The key words associated with these processes include: paraphrase, give, classify, write, infer, compare, and explain (Department of Curriculum Development and Evaluation, 1990; Anderson, et al., 2001).

C. Apply: This means using the guidelines or principles a student or learner has acquired in different situations to understand similar situations, or to solve similar problems if 
those situations were problems. The cognitive processes involved in dealing with equivalent situations or following or using certain principles to solve similar problems include: implementing and executing. The key words associated with these processes include: divide, use, give an example, demonstrate, and illustrate (Department of Curriculum Development and Evaluation, 1990; Anderson, et al., 2001).

D. Analyze: It means to break materials into pieces, parts or components and explain how these pieces relate to each other and to the whole structure. The cognitive processes involved in breaking down materials and explaining how they relate to each other and to the whole include: differentiating, attributing, and organizing. The key words associated with these processes include: distinguish, structure, and determine (Department of Curriculum Development and Evaluation, 1990; Anderson, et al., 2001).

E. Evaluate: It means judging the quality or condition of something or a situation based on set standards or criteria. The cognitive processes involved in judgment of the quality of information or materials include: critiquing and checking or finding out. The key words associated with these processes include: determine and judge (Department of Curriculum Development and Evaluation, 1990; Anderson, et al., 2001).

F. Create: It means to form a whole by bringing parts together, or re-organize parts to form a new whole or structure or pattern. This is a highly demanding process or category. The cognitive processes involved in creating something, or a whole, or re-organizing parts of something to form or build a whole include: generating, producing, and planning. The key words associated with these processes include: plan, generate, design, produce, construct and invent (Department of Curriculum Development and Evaluation, 1990; Anderson, et al., 2001).

\subsection{The Philosophy or Theory Underlying the Outcome-Based Education (OBE) Curriculum Design Approach}

In developing an OBE curriculum, the curriculum developer identifies exit outcomes before developing the curriculum (Spady, 1988). This is the reverse of the traditional approach to curriculum development. Spady (1988) states that: "In Outcome-Based Education, exit outcomes are a critical factor in designing the curriculum: you develop the curriculum from the outcomes you want students to demonstrate, rather than writing objectives for the curriculum you already have" (p6). Spady (Kaliannan and Chandran, 2012) approaches the understanding of OBE in two ways: (1) The first approach is focused on students' traditional way of learning where the emphasis is on students' mastery of content or subject matter by achieving classroom based outcomes, that is, learning outcomes of a lesson. In the traditional system, these would be learning objectives. (2) The second approach focuses on long-term outcomes or exit outcomes which describe what the student will do or will be in the future. It is the second one that Spady is interested in (Kaliannan and Chandran, 2012). Spady refers to the first approach as traditional/transitional $\mathrm{OBE}$ and the second approach as transformational OBE, respectively (Kaliannan and Chandran, 2012). Spady (1988) also emphasizes that the new system of curriculum design and instruction (that is, OBE) will make all students learn. 
For example, Spady (1988) says: "From my perspective, that means having all students learn well, not just the fastest, the brightest, or the most advantaged." This means that the current system of education, which relies heavily on classroom or lesson objectives and with a curriculum designed from readily designed content or subject matter, fails to provide education for students whose ability is mixed or discriminates against the less bright or less gifted students.

\section{Literature Review}

Since the main focus of this research is to find out the contribution of OBE to teaching, learning and assessment in a classroom set up, the literature review will focus on both the strengths and weaknesses of the use of outcomes. This approach will give a balanced analysis of the use of outcomes in a classroom situation.

\subsection{Strengths of Using Outcomes for Teaching in a Classroom Situation}

Spady (1988) uses a programme he calls The High Success Programme (HSP) as an example of the success of Outcome-Based Education (OBE). He says that the programme was founded in 1980 and that its membership has since grown to around 2,000 comprising educators in Canada and the United States of America (USA) (Spady, 1988). Those who are interested in the HSP join it through a network called Network for Outcome-Based Schools (NOBS) (Spady, 1988). Spady (1988) is the founding director of the HSP programme.

Spady (1988) says that since the HSP programme was founded he has worked with administrators and teachers on its implementation in various member states in the USA (for example, Arizona and Illinois) and these states are now enjoying its fruits. Spady (1988) states: "I have worked with hundreds of teachers and administrators who are now experiencing the positive impact of the OBE paradigm on curriculum organization, teaching , student motivation and learning, and instructional leadership"(p6).

Spady (1994) says that in order for a student to learn successfully (to do his/her work well or perform successfully the learning task at hand), he/she needs to be exposed to a learning environment which consists of three components: content knowledge, outcome/competence, and confidence/ character (Spady, 1994). He calls the whole model the Learning Performance Pyramid (Spady, 1994). On page 82 of his book, Spady (1994) gives a model which he calls: 'Face 1 OBE: Classroom Reform (Figure 4.1) and explains that the model illustrates that in implementing this level of OBE the activities of the traditional classroom will remain unchanged; he states: "...Leaves achievement measures, testing, grading, and reporting largely unchanged except for consistent use of "second chances" on tests and assignments" (Spady, 1994). The author, researcher or writer of this paper thought that in implementing outcomes, classroom or learning objectives needed to be replaced by learning outcomes (which should be different from learning objectives) but it is surprising that Spady maintains that nothing in the classroom will change. This can be interpreted to mean that Spady cannot differentiate between learning outcomes and 
learning objectives. The latter (learning objectives) are used in the traditional curriculum. Spady wants learning objectives replaced with learning outcomes. If there is confusion between learning outcomes and learning objectives for educational philosophers (for example, Spady), then there will be more confusion for implementers, primarily the teachers.

Yusoff, Fuaad, Yasin and Tawil (2014) conducted a study to investigate if programme outcomes were achieved when OBE education programmes were implemented. The researchers used a method of research called meta-analysis which compares the findings of existing research with empirical evidence (that is, current data or field notes). A sample of 20 research studies was used to generate different effect sizes and this enabled the researchers to compare these effect sizes and this gave them some information as to whether the outcomes of OBE education programmes were achieved or not. The research studies were obtained by searching from several databases which included: ERIC, Scopus, Emerald Full text, EBSCOHOST (eBook Collection), Sciences Direct, ProQuest Dissertations and Theses, ISI Web of Science, and JSTOR. The grand total of all samples used in all the 20 research studies was 16160. The grand sample of 16160 produced a total effect size of 0.968365 . The standard deviation for this effect size was 2.1084. These research studies used different research methods, but this did not cause much variation in the findings, indicating that when the meta-analysis research method is used there is little variation in the findings. The effect sizes were found to be large, indicating that students did well in the achievement of learning outcomes (LO) and programme outcomes (PO). The overall finding was that OBE improves educational achievement. However, there was no explanation given as to how OBE brought about an improvement in educational achievement.

Armstrong (1999) states that OBE has several strengths and he lists them as follows: it improves student performance, it focusses student attention on learning rather than on time-saving, it raises student expectation on the side of the teacher, it provides the student with flexible learning strategies or methods which promotes mastery learning to take place, it provides the student with a variety of teaching and learning strategies which cater for mixed ability learners, it gives learners responsibility for their own learning, it enhances staff commitment to student learning, it eliminates complete or lifelong failure (believes that all students can learn; no student fails) of students and poor academic achievement or standards, and finally, it allows all stakeholders in the education of the learner to participate. He, however, does not explain how the OBE education system or curriculum executes these strengths. It is typical for proponents of the OBE system of education to praise it as better than conventional or traditional education systems or curricula but failing to elaborate on the processes involved in achieving the stated (or said) strengths.

\subsection{Weaknesses of Using Outcomes for Teaching in a Classroom Situation}

Mbingo (2006) carried out a study to find out the problems that teachers faced when the new curriculum, which was based on OBE, was introduced in South Africa. The new 
curriculum was also called Curriculum 2005 and it was introduced at Foundation Phase level (Grades 1,2 and 3). Grades 1,2 and 3 are entry levels to primary education in government or public primary schools in South Africa. The study was guided by the following objectives (Mbingo, 2006):

- To investigate the problems associated with the introduction of the new curriculum.

- To find out the teachers' level of participation in the implementation of the new curriculum.

- To use the findings of the research to provide a set of conclusions and recommendations for the Department of Education, Curriculum Specialists and teachers which will hopefully enlighten these departments or officials with some insight on the burning issues of the implementation of Curriculum 2005 in the Foundation Phase of primary schools in South Africa.

The researcher used the qualitative research method. The whole population was used instead of drawing a sample. The researcher used two data collection methods or techniques, and these were interviews and observation. Using the whole population may not be a flaw in a research as such if the figure for the population is given but in this research it is not given. A researcher can do a good or credible research using a population as a sample as long as the data is collected correctly. Despite the use of a population without indicating the number, Mbingo's study (2006) remains interesting to the reader because the topic is interesting.

Mbingo (2006) found that there were various problems that teachers experienced when the new curriculum was introduced at Foundation Phase in South African government or public primary schools. On the contrary, students also experienced some problems in learning as a result of the introduction of the new curriculum (Curriculum 2005). Teachers found themselves teaching students or pupils to construct sentences instead of teaching them vowels or consonants first. The researcher said that pupils were taught how to construct sentences without knowing vowels such as 'a,e,i,o.u' (Mbingo, 2006) and consonants. The research did not give examples of consonants which teachers were to teach at that level (Foundation Phase). The researcher blames the OBE education system for abolishing vowels and consonants and requiring students or pupils to jump into sentence construction without a base (Mhingo, 2006). This is a weakness for a system that is viewed by its proponents as bringing about some improvement in student achievement or learning.

The author states that the OBE system is confused mainly because of the big words it uses. In addition, the author states that children from townships find it hard to cope with the new education system or curriculum as it comprises big words which confuse them (Mhingo, 2006). This means that children, who are mainly from townships, do not have sufficient background knowledge on which to build new knowledge.

Armstrong (1999) states that there are several weaknesses of the OBE education system and they include: it is behaviouristic, fragmented and machinistic (that is, its emphasis is on student behaviour; it is mechanical, that is, it treats a learner as an object 
which is subject to control instead of deciding its own destiny; it is fragmented, meaning that it is not one solid whole but pieces that move toward or from different directions); it treats knowledge as an end on itself or instrumental or a one-directional phenomenon, not something that can be used in a variety of ways; it stifles the inquiry and creativity mindedness of learners; it promotes outcomes which are dictated by states or districts not intentions of the learner; it may promote outcomes that are unlawful or illegal; it may promote a set of outcomes for which they may not be a consensus as to whether all students will benefit from them; it "waters down" or "dumbs down" the curriculum as the content is simplified to ensure that all students learn - those who fail are made to "pass"; it promotes the teaching of values instead of making students master basic skills and knowledge; it promotes the learning of outcomes which are stated in ambiguous and subjective terms and therefore hard to measure on the basis of objectivity; it ignores the fact that in order to assess high order thinking you first of all need to equip the learner with basic factual knowledge; it overloads the teacher by requiring students' portfolios which demands attention to individual student assessment, teaching, record keeping, planning enrichment strategies for the learner, and executing remediation techniques; it finally, it puts gifted students at a disadvantage by slowing them down in terms of the pace of learning.

The weaknesses of the OBE education system outlined by Armstrong (1999) are exhaustive to the extent that they are not an encouragement to those curriculum designers and education policy makers who may be about to replace their education systems with OBE. Education reformers who are currently in that path need to think twice before they implement OBE. They also need to learn in those countries where OBE has failed before they make an attempt. The author of this article recently attended a workshop in Botswana on the preparation for the implementation of OBE in Botswana public secondary schools and found that the participants (including the author) were struggling to change from conventional or traditional education system (one that uses learning objectives) to OBE as the more they effected the changes the more the curriculum remained the same. Interesting! This shows that OBE proponents are confused as to what they want to change conventional or non-OBE education systems to. Explanations on OBE terminologies are never user-friendly and hence the difficulties encountered in attempts to implement OBE.

The weaknesses of OBE outweigh the strengths, as Bray (1997) "argues that the criticisms of OBE outweigh the cited benefits" (p10). This is a good observation that potential implementers of OBE should take note of. This is because, normally for an innovation to be adopted, the strengths should outweigh the weaknesses with regard to the innovation to be adopted. The other way round is likely to be a disaster.

\section{Statement of the Problem}

The University of Botswana has a long history offering courses that use objectives as measures of academic achievement. As a result, its graduates who are trained as teachers 
in primary schools, secondary schools and other related institutions of learning including those at tertiary levels use objectives when teaching or lecturing. With the establishment of the Botswana Qualifications Authority (BQA) (established by the Botswana Qualifications Authority Act, Number 24 of 2013) all institutions of learning in Botswana are now required to register with BQA to be accredited and there is a requirement which they need to meet in order to register with this institution or board. This requirement is that these institutions should prepare their courses so that they are compliant with Outcome-Based Education (OBE). To be compliant, these institutions must meet one important criterion: their courses and programmes should use outcomes as the basis of their measure of academic achievement in lieu of objectives. Outcomes are viewed as bringing more improvement to objectives as compared to objectives. This research study seeks to investigate the improvement of teaching and learning or academic achievement that the use of learning outcomes is said to bring to institutions of learning in Botswana as compared to the use of learning objectives.

\subsection{Research Questions}

This research study used the following questions as a guide:

1) What is the difference between lesson (or learning) outcomes and lesson (learning) objectives?

2) How are learning outcomes used in writing question items for tests and examinations?

3) How do learning outcomes improve teaching and learning or academic achievement and assessment in comparison with the use of learning objectives?

\subsection{Research Objectives}

This research study used the following objectives as a guide:

1) To find out the difference between lesson (or learning) outcomes and lesson (learning) objectives.

2) To find out how learning outcomes are used to write question items for tests and examinations.

3) To find out how learning outcomes improve teaching and learning or academic achievement, and assessment, in comparison with the use of learning objectives.

\subsection{Purpose of the Study}

Objectives have been used for a long time in the education system of Botswana. They have served their purpose well during the time they have been in use. With the establishment of BQA educational institutions in Botswana are required to change from objectives-based teaching and learning (OBTL) to Outcome-Based Education (OBE). As the name and abbreviation imply, OBE is based on the use of outcomes in lieu of objectives. The purpose of this research study is to explain how the use of outcomes improves teaching and learning or academic achievement vis-à-vis the use of objectives. 


\subsection{Significance of the Study}

This research study is very significant to various stakeholders of the education system in Botswana. These stakeholders include: teachers of both junior and senior secondary schools, lecturers of tertiary education institutions, curriculum developers, education officers, and education policy makers. Techers and lecturers are implementers of the curriculum, curriculum developers develop the curriculum, education officers advise teachers on how to interpret the curriculum, and education policy makers guide schools on how they should operate to ensure that curriculum implementation is a success.

\subsection{Limitations of the Study}

This study used purposive sampling which means drawing a sample from a population because it is convenient to do so. A researcher selects a sample on the basis of his/her judgment. The researcher uses his/her judgment to decide who to choose from the population that he/she views as appropriate for the study. This means that he/she cannot generalize the findings since the sample chosen is a non-probability sample instead of being a probability sample. Another limitation of purposive sampling is that the researcher using this type of sampling procedure is prone to be biased in carrying out the research process. This is primarily due to the fact that the researcher can never be certain that he/she has done the judgment well or in an acceptable manner. In short, the researcher's judgment is almost always subject to questioning. Last but not least, respondents may manipulate the data which might lead the researcher to conclude as he/she wishes or the results could be the opposite of what he/she anticipated.

\section{Methodology}

This research study used qualitative research method as the data used was qualitative in nature, that is, it was not numerical. The study did not use human subjects. It used document analysis as a data collecting instrument and the documents were selected course outlines which met the criterion for selection which was basically that they should be OBE/Outcome-based compliant. These course outlines were for Social Studies courses. Social Studies is one of the specializations which students choose as one of their major or minor subjects if they are enrolled for the Bachelor of Education (Secondary) Programme offered by the University of Botswana. They (course outlines) have not yet been used because the University of Botswana is still in the preparation stage prior to the implementation of Outcome-based Education (OBE). Only five (5) of the available OBE/Outcome-based Education compliant Social Studies courses have been selected to serve as illustrations in the discussion on this paper. The selection of the sample was, therefore, purposive. 


\subsection{A Sample of Outcome-based/OBE Compliant Social Studies Courses to be Offered at the University of Botswana}

Courses EPS 203, ELC 212, ELC 211, ELC 403, and ELC 461 were selected for the research study. Only the outcome sections of the course outlines have been selected because they are the areas of focus.

\section{EPS 203: Indigenous Peoples and their Environment}

4.1 Explain how different people adapt to their environment e.g. Basarwa, Aborigines, Maasai, and Maori, etc.

4.2 Analyze the socio-cultural, political and legal issues of indigenous peoples of the world.

4.3 Critically analyze issues of race, class, gender, inheritance, identity, language and culture and how they are interrelated.

4.4 Discuss the role of culture in shaping the lifestyle of societies.

4.5 Examine the relationship between indigenous peoples' culture and environments.

4.6 Develop within students the ability to be reflective, critical and independent learners through online discussions (Blackboard/Moodle).

4.7 Develop an understanding of the role and effect of stereotypes on the lives of indigenous people and how these can be confronted and eliminated within a classroom setting.

4.8 Develop PowerPoint Presentations.

4.9 Evaluate the status of indigenous peoples around the world.

4.10 Critique their own prejudices and stereotypical attitudes towards indigenous peoples of the world.

4.11 Engage in group and class discussions.

4.12 Summarize reading materials on indigenous peoples of the world.

4.13 Analyze video materials on indigenous peoples of the world.

4.14 Write a well-researched essay.

\section{ELC 212: Social Services and Policies in Botswana}

i. Evaluate the role of key stakeholders involved in the provision and delivery of social services.

ii. Apply essential knowledge and skills to use ICT to support $21^{\text {st }}$ century [learning] to understand social problems and policies.

iii. Examine and appraise past and current social policies and welfare programmes with a view to recommending changes that [can be effected] to positively affect vulnerable groups such as the poor, youth, women, and people living with disabilities.

iv. Explain the importance of linking national and social policies and programmes to the attainment of the goals of Vision 2036. 


\section{ELC 211: Introduction to Development Issues and Perspectives}

1. Define the concept development and its related key concepts.

2. Identify and discuss indicators of development.

3. Discuss the factors which promote development.

4. Assess, explore, and evaluate theories of development.

5. Examine development constraints/challenges that face Third World nations/countries and suggest solutions to identified constraints/challenges.

\section{ELC 403: Economic Co-operation and Integration}

i. Appropriately define the key concepts associated with economic co-operation and integration.

ii. Evaluate the significance of selected regionalization projects from a comparative perspective.

iii. Critique successes, problems, constraints and challenges facing efforts aimed at promoting regional economic co-operation and integration.

iv. Develop strategies for addressing problems/ constraints /challenges associated with issues and policies around economic co-operation and integration.

\section{ELC 461: Human Rights Issues}

1. Define the term human rights.

2. Discuss the importance of the Universal Declaration of Human Rights.

3. Examine group-specific rights, for example, the rights of women, the rights of children, the rights of minorities, etc. within the context of human rights (Articles 1-30 in the Universal Declaration of Human Rights document).

4. Examine the role of the law (or courts) in protecting human rights.

5. Discuss the role of Human Rights Organizations in promoting and protecting human rights in Botswana, for example, Amnesty International, Ditshwanelo (Botswana Centre for Human Rights), etc.

\subsection{Data Analysis and Discussion of Findings}

The data was analyzed in terms of the research questions and research objectives of the study. The key data were the outcomes that appeared on the selected course outlines that appeared on the Methodology section of this paper. These course outlines were as follows: EPS 203, ELC 212, ELC 211, ELC 403, and ELC 461. Research questions 1, 2, and 3 and research objectives 1,2, and 3 formed three themes under which the data was analyzed, and these were: Differences between Lesson Outcomes (LOU) and Lesson Objectives (LOB), The use of outcomes in writing question items for tests and examinations, and lastly, the improvement brought about by the use of outcomes in teaching and learning or academic achievement, and assessment, in comparison with the use of learning objectives. The discussion will be reinforced by reference to available literature. 


\subsubsection{Differences between Lesson Outcomes (LOU) and Lesson Objectives (LOB)}

Considering the nature of the course outlines that were used in this study as examples and the literature on OBE, there is no clear distinction between outcomes and lesson objectives. Spady (1994), who many consider to be an authority in OBE defines outcomes as: "...clear learning results that we want students to demonstrate at the end of significant learning experiences" (p2). Spady (1994) further defines an outcome as: "...the ability to apply mental processing through the use of demonstration processes and verbs (like write, organize, design, or produce) corresponds to the definition of an outcome explained in this book" (p68). If you read Spady (1994) further you will find that he quotes words such as "describe" and "explain" as examples of what he calls "...observable action verbs" (p13) necessary when writing or expressing lesson outcomes. In educational measurement, the word observable is normally used interchangeably with measurable and it is used in the context of using objectives to determine the intellectual level of a learner with regard to educational achievement in a classroom setting. The description of outcomes that appears here fits lesson objectives in its entirety.

On page 13, Spady (1994) gives an example of an outcome, expressed in a question form and it reads: "...explain the major causes of inflation in capitalist economies..." This statement is definitely a lesson objective. On page 7, Spady (1988) mentions several types of outcomes in descending order of levels: Exit Outcomes, Programme Outcomes, Course Outcomes, Unit Outcomes, and Lesson Outcomes. The fact that he uses the phrase lesson outcomes suggests that these types of outcomes are used in a lesson set up instead of lesson objectives. I have read most of Spady's work and I have never come across a sample of a lesson plan that demonstrates the use of lesson outcomes. The absence of such information urges me (the author of the paper) to conclude that there are no such phenomena as lesson outcomes. Only lesson objectives exist, and these are what Spady probably refers to as lesson outcomes.

One of the outcomes in EPS 203 is expressed with the word "engage". This word does not seem to fit the criteria for lesson objectives or lesson outcomes that have been presented in this discussion: that an outcome or objective should be expressed with words that indicate observable or measurable action, for example, explain and describe. If the word engage is an example of an outcome, then the word outcome is a problematic word because it is not easy to measure as Spady said outcomes are measurable. This adds to the confusion that is already there as earlier observed in some parts of this paper.

In order to further understand outcomes, especially those related to the direction or perspective of other words which do not fit the criterion of objectives, for example, engage, the author wants to use examples given by Brady (1997). This discussion will be related to Table 1. 
Table 1: Sample of state English Profile for a Student STRAND: TALKING \& LISTENING Text and Context

\begin{tabular}{|c|c|}
\hline Outcome & Evidence of progress \\
\hline $\begin{array}{l}\text { 1.1 Shows emerging awareness of school } \\
\text { purposes and expectations for using spoken } \\
\text { language. }\end{array}$ & $\begin{array}{l}\text { - } \quad \text { Understands classroom routine and rules. } \\
\text { - } \quad \text { Co-operates with others on task. } \\
\text { - } \quad \text { Uses talk to establish relationships with others. }\end{array}$ \\
\hline $\begin{array}{l}\text { 1,2 Interacts informally with teachers, peers and } \\
\text { known adults in structured classroom activities } \\
\text { dealing briefly with familiar topics. }\end{array}$ & $\begin{array}{l}\text { - } \\
\text { - } \quad \text { Uttempts to give directions to mothers. } \\
\text { - } \quad \text { Asks and answers questions. Use who, what, } \\
\text { when, where. }\end{array}$ \\
\hline $\begin{array}{l}1.3 \text { Recognises that there are different kinds of } \\
\text { spoken texts. }\end{array}$ & $\begin{array}{l}\text { - Makes connections between } 1{ }^{\text {st }} \\
\text { language/English. } \\
\text { - Compares greetings between home/school } \\
\text { language. }\end{array}$ \\
\hline 1.4 Monitors communication of self and others. & $\begin{array}{l}\text { - } \quad \text { Listens to a speaker and contributes. } \\
\text { - } \quad \text { Self-corrects to clarify meaning. } \\
\text { - } \quad \text { Uses conjunctions. }\end{array}$ \\
\hline
\end{tabular}

Source: Adapted from Brady, 1997, page 62.

If you look at outcomes 1.1, 1.2, 1.3, and 1.4 you will find that almost all of them do not fit the criterion for objectives which states that they should be measurable or stated in observable terms. These are examples of outcomes given by Brady (1997). The right column gives the criteria for achievement of the outcomes given on Table 1 . The criteria do not represent the knowledge and skills that students would normally learn in a typical classroom in a typical secondary school. The criteria are more of values rather than knowledge and skills that students normally learn in secondary schools. The researcher has read much of the readings on OBE and none of them has given a distinction between lesson outcomes and lesson objectives. Spady, in particular, who is considered one of the gurus of OBE also fails to define outcomes; he has never given a definition of outcome in most of his works or writings that I have read so far. He once gave an example of an outcome in the form of a question and it was, in fact, based on an objective. He said: "...explain the major causes of inflation in capitalist economies..." (Spady, 1994, p13). Can we then conclude that an outcome is an objective? Yes, we can. Based on this instance, an outcome is, therefore, an objective and vice versa. Jansen (1997) summarizes this situation by saying: "First, the language of innovation associated with OBE is too complex, confusing and at times contradictory" (p3). He is emphasizing the confusion that a researcher comes across in trying to understand the essence of outcomes in OBE or even the whole information on the nature of OBE. The fact that the information on outcomes and OBE is often presented in confusing and contradictory language could be the primary cause of why OBE proponents put more emphasis on exit outcomes rather than on lesson outcomes (or objectives) because they confuse the two. This may be a result of the fact that they are not sure as to whether lesson objectives and lesson outcomes are different or the same. If they are sure of this situation, then they must give precise definitions for the two terms (lesson objectives and lesson outcomes). You do not bring about change by calling a spade a 
digging fork! This is my concern. In fact, such a situation makes one to conclude as in an article written by Kumar (2010) on a study conducted in 1999 as a critique of C2005 (the OBE curriculum of South African education introduced after 1994) that it resulted in very little learning, if there was any. Kumar (2010) states: “...in actuality very little learning was taking place" (p10).

\subsubsection{Use of Outcomes to Write Question Items for Tests and Examinations}

The author of this paper has never seen a test or examination where outcomes have been used to prepare question items. However, the author has seen tests and examinations where objectives have been used for writing or preparing question items. However, one needs to emphasize that OBE practitioners often do not emphasize tests and examinations assessments and instead they emphasize the use of portfolio assessment. This is primarily because they emphasize assessment of other phenomenon rather than the "hard knowledge or content" that we are used to in the current education system. The paragraph that follows will briefly discuss this point.

Available literature on outcome-based education indicates that assessment of students is based on the strategies set forth on each student's file or portfolio. In portfolio assessment, tests and examinations are rarely, if not, hardly, used. As a result, whenever assessment is mentioned in portfolio assessment, the issue of teacher overload arises. This is because the teacher is required to ensure that the learner is assessed in accordance with the guidelines set forth in the learner's portfolio. In addition, Spady (1994) earlier said that outcomes should be expressed in "...observable action verbs" (31). One other point is that these statements called outcomes, if they were to be written with observable action verbs they would be observable or measurable, which is a characteristic of objectives. Furthermore, if outcomes were to be expressed in terms of action verbs, as it has already been observed, then the tests and examinations items based on outcomes would primarily test values, attitudes and other phenomena rather than test knowledge (content) and specific skills as the current education system does or dictates. Jansen (1997) summaries this point by saying: "...OBE trivializes curriculum content even as it claims to be a potential leverage away from the content coverage which besets the current education system. Children do not learn outcomes in a vacuum. Curriculum content is a critical vehicle for giving meaning to a particular set of outcomes"(p7). This means that learners who learn in situations where lesson outcomes of the nature of those referred to in this section of the paper end up with superficial knowledge and skills compared to the knowledge they would have acquired in an environment where "hard knowledge or content and high level skills" are offered. This refers to the knowledge or content learners acquire from the education system that OBE tries to replace in the current Botswana education context. In summary, replacing the current education system or essentially, the objectives-based curriculum with OBE/outcomes system of education is like committing genocide on the curriculum because you are replacing something that works with something that is less than working. This point is clear and needs no further emphasis. This is why curriculum developers in Botswana are just implementing OBE not that it is worthwhile. 


\subsubsection{Using Outcomes to Improve Teaching and Learning in Comparison with the Use of Objectives}

Improving the teaching and learning aspects of education simply means improving the quality of education. There have been many debates regarding the proper definition of what education quality means. However, Botha (2002) has identified three elements that determine the quality of education, and these are: the performance of teachers, the performance or achievement of learners, and the relevance of the curriculum to the needs of the learners. In view of these three aspects or dimensions, if they are all performing at their highest, then the best quality of education is being offered. In order to make our discussion more focused and interesting, let us identify one key factor that forms a point of intersection of the three factors that Botha (2002) uses to measure education quality: this factor is the outcome or outcomes, if expressed in plural form. If we adopt the perspective of outcomes as determinants of quality in education in the context of OBE, the improvement in the quality of education becomes questionable or doubtable. This is because when lesson objectives (or outcomes in the OBE jargon) are used, there is confusion as to the difference between the two terms. OBE proponents confuse lesson objectives and lesson outcomes, and we end up not knowing what they use in their teaching. Moreover, they emphasise exit outcomes at the expense of lesson objectives or lesson outcomes. This obviously means that the emphasis is on the outcomes that occur on the periphery of teaching not the fundamentals or essence of the teaching process. The fundamentals or essence of the teaching process are the activities that take place in the classroom under the guidance of, or supervision by the teacher. These are the things that the teacher assesses on students in the end to get feedback on the effectiveness of his/her teaching. The quality of classroom activities (guided by objectives, of course) determines the quality of exit outcomes, whatever they are or supposed to be. On the basis of this observation, we can conclude that they (lesson outcomes) produce weak learners in both content or knowledge and skills required for success in careers of their choices. The proponents of OBE most often emphasize that students who have acquired knowledge and skills under OBE education or curricular satisfactorily demonstrate that they have acquired these three components of education (performance of teachers, performance or achievement of learners, and relevance of the curriculum to the needs of learners), but they fail to provide tangible evidence for that observation or assertion.

The author has extensively read Spady's works (for example, 1988 and 1994 and there is nowhere in those readings where outcomes have been differentiated from objectives or vice versa. In fact, the "classical" (his best) example of an outcome that Spady gave in his works (1994) is expressed with the action word or verb explain, which is the essence of an objective. It is this confusion of information, among other problems that may be identified, if any, that makes the implementation of OBE as an alternative to other education systems or curricular, very difficult. This is why Mbingo (2006) refers to the implementation of an OBE curriculum as a mess. In fact, Mbingo (2006) states that an OBE curriculum focusses mainly on the affective domain rather than on the cognitive domain which deals with academic content or knowledge. Mbingo (2006) says on 
outcomes: "They are largely in the affective domain, describing mental processes such as attitudes and sentiments - behavioural and social outcomes rather than knowledge, skills and other cognitive outcomes" (p21). Other authors refer to this education mess that Mbingo is talking about as mis-education, meaning that it lacks clarity as to what it really is and that it is also not academic - it is mere confusion and confusion goes with poor quality. In essence academic means content knowledge as opposed to such things as attitudes which are mainly found in the affective domain of Bloom' Taxonomy. Some readers describe $\mathrm{OBE}$ as something else but not education because they characterize education as mainly dominated by the cognitive domain because it equips learners with the knowledge, skills and attitudes required for the production or graduation of professionals in different fields of study who drive economic development of various nations. It is therefore, important to summarize the difference between OBE and objectives - based system of education as being on emphasis - the former (OBE) emphasizes knowledge derived primarily from the affective domain while the latter (objectives-based education system proponents or practitioners) emphasize knowledge primarily derived from the cognitive domain.

\section{Conclusion}

There is no clear distinction between lesson outcomes and lesson objectives. This is because the available literature, including the course outlines that were analyzed to generate data for this research paper, do not clearly make that distinction. In fact, the two sources of data fail to distinguish between lesson outcomes and lesson objectives. Even Spady, the key proponent of OBE fails dismally whenever he makes an attempt to differentiate between lesson outcomes and lesson objectives. This is backed by the evidence that whenever he tries to distinguish between the two entities (lesson outcomes and lesson objectives) he finds himself emphasizing that lesson outcomes consist of action verbs such as explain and describe which are themselves used to write or prepare tests and examinations in a system that uses lesson objectives for teaching and learning.

Spady has not been able to show us how lesson outcomes are used to set question items for tests and examinations. He emphasizes portfolio assessment over other forms of assessment. Portfolio assessment emphasizes student giving oral and written feedback to teachers or facilitators instead of sitting for tests and examinations as sources of feedback for the teacher.

When it comes to assessment, OBE focuses more on the content that primarily resides in the affective domain instead of focusing on the knowledge contained by the cognitive domain. This differences in areas of focus means that the two systems of education, that is, OBE and the objectives-based education cannot be compared because they do different things, or their businesses are different. In this case, we cannot say that one system improves the other. The term improvement basically means making better, but in replacing the objective-based education with OBE you are not improving anything, you are doing something different. This is especially true when you replace a good system with a system that is worse than the previous one in terms of the results or 
products. A person who graduates from an OBE system of education is less competent in content, attitudes and skills than one who graduates from an objectives-based education system. This is one of the factors that made OBE to fail in some countries. This is because the jargon used to describe its contents is confusing and worse of it, it is confusing to the potential implementer. In addition, portfolio assessment is often pronounced in OBE education system. Portfolio assessment is primarily dominated by students telling the teacher how they feel about their learning and the student replies by claiming that he/she has learnt a lot. In other words, lack of serious assessment guided by the teacher and focusing on "hard" content derived in relation to the cognitive domain produces graduates who are weak academically. Such graduates find it hard to fit in the modern economy.

In summary, the reader will find out that OBE is a challenging and confusing system of education. As a result, it has been phased out in a number of countries. Those countries which are aspiring to implement OBE will abandon it out of dismal failure to implement it. However, this is not a form of discouragement to adopt or implement it. They should do what they choose.

\subsection{Recommendations}

The recommendations that follow are intended for guidance to those institutions or educational systems which seek to change from objectives-based learning to OBE or those which seek to be accredited while sticking to the objective-based education system.

1) In view of the difficulties encountered when trying to differentiate between learning objectives and learning outcomes, it is recommended that educational institutions that use learning objectives should be accredited without requiring them to change from using objectives to outcomes.

2) Those institutions that use outcomes for learning and teaching should be guided on how to use learning outcomes to write test or examination questions.

3) Those educational institutions that use learning outcomes instead of learning objectives in teaching and learning should change focus and focus more on the cognitive domain rather than on the affective domain because the cognitive domain focuses on the content required by most professions.

\section{References}

Anderson, L.W. \& Krathwohl, D.R. (2001). A Taxonomy for Learning, Teaching and Assessing: A Revision of Bloom's Taxonomy of Educational Objectives: Complete Edition. New York; Lognman.

Armstrong, C.A. (1999). A Constructivist Critique of Outcomes-Based Education. A Research Report submitted to the Faculty of Education, University of the Witwatersrand, Johannesburg, in partial fulfillment of the requirements for the degree of Master of Education by Coursework. Unpublished Report. 
Asimi, K. (2014). Outcome-Based Education with Special Reference to the International Education Agency in PNG. Contemporary PNG Studies; DWU Research Journal. Vol. 20. 103-110.

Botha, R.J. (2002). Outcomes-Based Education and Educational Reform in South Africa. International Journal of Leadership in Education. Vol. 5 (4), p361-371.

Bloom, B.S., Engelhart, M.D., Furst, E.J.., Hill, W.H. \& Krawthwohl, D.R. (1956). Taxonomy of Educational Objectives; The Classification of Educational Goals. Handbook 1. Cognitive Domain. New York: David McKay Company.

Brady, L. (1997). Assessing Curriculum Outcomes in Australian Schools. Educational Review. Vol. 49, No.1, p57-65

Department of Curriculum Development and Evaluation. (1990). Botswana Social Studies Teaching Method: A Resource Book for Teachers. Macmillan Botswana: Gaborone.

El-Maaddawy, T. \& Daneen, C. (2017). Outcomes-Based Assessment and Learning; Trialling Change in a Postgraduate Engineering Course. Journal of University Teaching and Learning Practice. Vol. 14, Issue 1. 1-19

Jansen, J.D. (1998). Curriculum Reform in South Africa: A Critical Analysis of OutcomesBased Education. Cambridge Journal of Education. Vol. 28 (3). 321-331.

Kalianann, M. \& Chandran, S.D. (2012). Empowering Students through Outcome-Based Education (OBE). Research in Education. Vol. 87, Issue 1. 50-63

Killen, R. (2000). Outcomes-Based Education: Principles and Possibilities. Paper.

King, J.A. \& Evans, K.M. (1991). Can We Achieve Outcome-Based Education? Educational Leadership.73-75

Kumar, A. (2010). A Synoptic View of Curriculum Studies in South Africa. Journal of the American Association for the Advancement of Curriculum Studies. Vol. 6, 1-16.

Lawson, M.J. \& Askell-Williams, H. (2007). Outcomes-Based Education. Discussion Paper.

Mbingo, S.J. (2006). An investigation into the implementation of the new curriculum by Foundation Phase teachers in Bethal, Mpumalanga. Mini-dissertation submitted in partial fulfilment of the degree of Magister Educationist in Curriculum Studies in the Faculty of Education at the University of Johannesburg.

Shmidt, M.J. (2017). The Perils of Outcomes-Based Education in Fostering South African Educational Transformation. Open Journal of Political Science. Vol. 7, 368-369.

Spady, W.G. \& Marshall, K.J. (1991). Transformational Outcome-Based Education gives schools a profoundly different means of transforming themselves. Educational Leadership. 67-72.

Spady, W.G. (1988). Organizing for Results: The Basis for Authentic Restructuring and Reform. Educational Leadership. 4-8.

Spady, W.G. (1994). Outcome-Based Education: Critical Issues and Answers. American Association of School Administrators: Arlington, Va.

Yusoff, N.F.A., Fuaad, Yasin, R.B.M. and Tawil, N.M. (2014). Achievement of the Program Outcomes in Outcomes Based Education Implementation - A Meta-Analysis. 
Proceedings of the 2014 International Conference on Industrial Engineering and Operations Management, Bali, Indonesia, January 7-9, 2014. be applied to their work. Under the terms of this license, no permission is required from the author(s) or publisher for members of the community to copy, distribute, transmit or adapt the article content, providing a proper, prominent and unambiguous attribution to the authors in a manner that makes clear that the materials are being reused under permission of a Creative Commons License. Views, opinions and conclusions expressed in this research article are views, opinions and conclusions of the author(s). Open Access Publishing Group and European Journal of Alternative Education Studies shall not be responsible or answerable for any loss, damage or liability caused in relation to/arising out of conflict of interests, copyright violations and inappropriate or inaccurate use of any kind content related or integrated on the research work. All the published works are meeting the Open Access Publishing requirements and can be freely accessed, shared, modified, distributed and used in educational, commercial and non-commercial purposes under a Creative Commons Attribution 4.0 International License (CC BY 4.0). 